\title{
MEAN REVERSION IN UNEMPLOYMENT: NEW FINDINGS FROM THE BALTIC TIGERS
}

\author{
Fumitaka FURUOKA \\ Asia-Europe Institute, University of Malaya, 50603 Kuala Lumpur, Malaysia
}

Received 22 August 2012; accepted 24 June 2014

\begin{abstract}
The tendency of the unemployment rate to revert to the mean value or the natural rate of unemployment has been one of the most discussed topics in macroeconomics. This study focused on three Baltic countries - Estonia, Latvia and Lithuania - as case studies to investigate unemployment dynamics. Three unit root tests were performed for this purpose: 1) the Augmented DickeyFuller (ADF) test, 2) the Seemingly Unrelated Regressions Augmented Dickey-Fuller (SURADF) test and 3) the Fourier Augmented Dickey-Fuller (FADF) test. The null hypothesis was that unemployment in the Baltic countries is a unit root process. As the findings revealed, the ADF test and the SURADF test failed to reject the null hypothesis of a unit root for all the three Baltic countries. However, the nonlinear FADF test could not reject the null hypothesis for Lithuania. This means that unemployment in Lithuania could be described as a stationary process. As such, it has the tendency to revert to a sustainable level. By contrast, unemployment in Estonia and Latvia would be best characterised as a non-stationary process where the unemployment rate lacks the mean reverting behaviour.
\end{abstract}

Keywords: mean reversion, sustainable unemployment, Baltic countries, unit root, nonlinear.

JEL Classification: E24, C22.

\section{Introduction}

The tendency of the unemployment rate to revert to the natural rate of unemployment is one of the most discussed topics in macroeconomics. However, the opinions regarding the mean reverting behaviour are contradicting. Some researchers support the natural rate hypothesis which proposes that the unemployment rate has an inherent tendency to revert to a sustainable level of unemployment or a natural rate of unemployment (Phelps 1967; Friedman 1968). Other economists advocate the hysteresis hypothesis which is based on the assumption that the unemployment rate will not revert to the natural rate of unemployment (Blanchard, Summers 1986a, 1986b; Gregory 1986). There also exist the alterna-

Corresponding E-mail: fumitakamy@gmail.com 
tive perspectives on unemployment dynamics, such as the persistence hypothesis and the structuralist hypothesis, which share the assumption that the unemployment rate has the mean reversion property. In other words, among the hypotheses about unemployment dynamics only the hysteresis hypothesis assumes that unemployment is a unit root process and, therefore, the unemployment rate has the mean reversion tendency.

Studies on the behaviour of the unemployment rate become especially relevant during an economic crisis or in the post-crisis period. In the case of the US economy, which experienced three recessions between 1990 and 2010, the existence of mean reversion was established in the research literature (Gustavsson, Osterholm 2011). However, as DeLong (2011) pointed out, in 2011 unemployment in the country was still relatively high at 9.2 percent. More importantly, despite the optimistic prognoses it was not certain whether the US unemployment rate would eventually revert to the average post-war (1948-2010) level of 6.1 percent. DeLong did not contend the fact that the US unemployment rate has the mean reversion tendency but he pointed out that this tendency had grown weaker.

The present article focuses on three Baltic countries - Estonia, Latvia and Lithuania and examines the mean reversion property in their unemployment rates. There were obvious similarities in the paths of unemployment in these countries over the period 2000-2011 (see Fig. 1). In the beginning of the 2000s, the unemployment rates kept decreasing and by the middle of the decade they reached their lowest levels. In 2008, there occurred a slight increase in unemployment and the average unemployment rate in the Baltic countries rose to 6.4 percent. The worst year of the decade in terms of unemployment was 2010, when almost one-fifth of the workforce in the Baltic countries was unemployed. However, after peaking at 18.7 percent in 2010, the average unemployment rate began to decrease and diminished to 14.7 percent in the following year (Eurostat 2012). This reduction in the unemployment rates is reflected in Figure 1 as the U-shaped curves of the unemployment paths. A question that arises is whether these U-shaped trajectories could be considered as empirical evidence for the existence of mean reversion? The current study aims to answer this question.

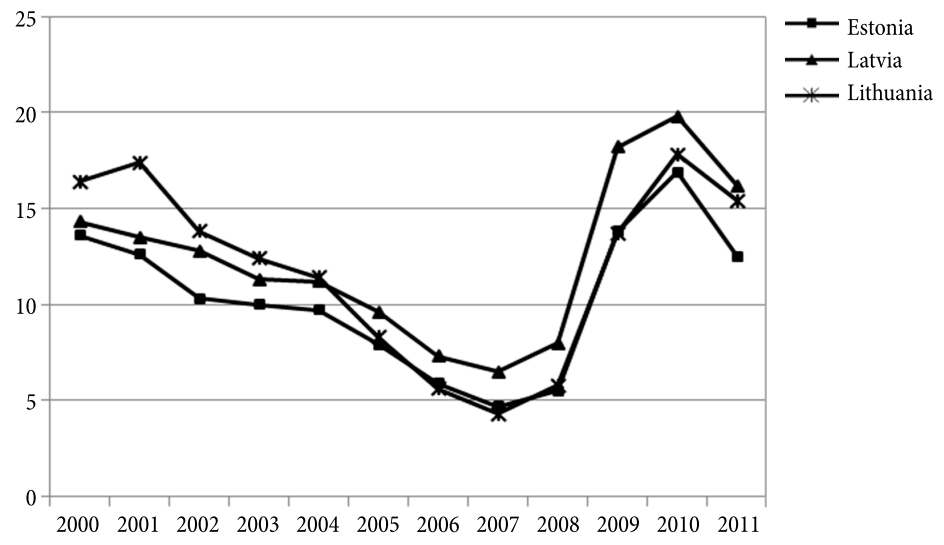

Fig. 1. Unemployment rates in the Baltic States (percentage) Source: Eurostat (2012). 
For this purpose it employed new estimation methods. In addition to the conventional ADF test (Dickey, Fuller 1979) this study carried out the panel analysis based on the SURADF test (Breuer et al. 2002) and the Fourier approximation based the FADF test (Enders, Lee 2012). The SURADF test is expected to yield better empirical results because it employs the Seemingly Unrelated Regression (SUR) that takes account of contemporaneous cross-correlations of the error terms (Breuer et al. 2002). Furthermore, the newly developed FADF test produces better results in studies on the nonlinear behaviour of the unemployment rates. According to Enders and Lee (2012), a Fourier approximation can capture unknown structural breaks or unattended nonlinearity in the deterministic component of a model.

This article has the following structure: subsequent to this introductory section, Section 1 gives a brief description of the economic performance of the three Baltic countries during the post-independence period. A review of the relevant literature is offered in Section 2. Section 3 describes the research method and reports the empirical findings. The last Section contains concluding remarks.

\section{Background of the study: the Baltic Miracle}

Estonia, Latvia and Lithuania have achieved a remarkable economic growth since the restoration of their independence in 1991. While many of the former USSR republics were struggling to transform their centrally planned economic systems into market-based economies, the Baltic Tigers set an example of a rapid and effective economic transformation. The policies aimed at economic liberalization adopted by the governments and the availability of a highly educated and relatively cheap workforce helped the Baltic countries to attract foreign direct investment (FDI). Miškinis and Reinbold (2010) pointed out that the lower wages had prompted several German multinational corporations (MNCs) to relocate their labour-intensive productions to the Baltic countries. The massive inflows of foreign productive capital during the 2000s helped the Baltic economies to attain the highest levels of economic growth in Europe (Matthews 2007). For example, while the average real GDP growth in the European Union (EU) area was 1.7 percent, Estonia's economy grew by 4.7 percent, Latvia's by 4.3 percent and Lithuania's by 5.0 percent.

Figure 2 shows real GDP growth rates in the Baltic countries and the EU area over the period 1996-2011. In 1999, the three countries experienced an economic downturn due to the Russian financial crisis that had occurred in the previous year. However, they were able to rapidly recover from the contagion effect of the crisis and beginning from the year 2000 their economies grew at high rates. In 2004, Estonia, Latvia and Lithuania joined the European Union which further spurred their economic performance. The leap of the "Baltic Tigers" came to a halt in 2008, when a new global economic crisis began unravelling. In addition, Greece's economic woes caused by the public debt crisis were spreading alarms all over Europe. Talks about the looming European sovereign debt crisis began when several EU countries faced similar to Greece's problems. Among the three Baltic countries, Estonia was least affected by the crisis which prompted a reputable international publication to 
comment that should a Baltic Tiger remain alive in the year 2011, it would surely be Estonian (The Economist 2010). Indeed, during the economic crisis Estonia did not experience serious problems caused by heavy government debt (see Fig. 3) and the country remained one of the healthiest European economies (Hannay 2011).

The ebbs and flows in the economic performance affect the labour market. Figures 4(a), 4(b) and 4(c) illustrate the main features of the labour markets in the Baltic countries between 1998 and 2012. The labour force participation rates (LFPRs) are shown in Figure 4(a). The LFPR is defined as the share of active population, meaning employed plus unemployed persons, in the total population. As the figure shows, the LFPRs in Estonia and Latvia followed similar time-paths: they were at their lowest levels in the early 2000s, and reached high levels in the end of the decade. In Lithuania, the LFPR was at its lowest in 2006; then it started to increase but remained lower than in Estonia and Latvia.

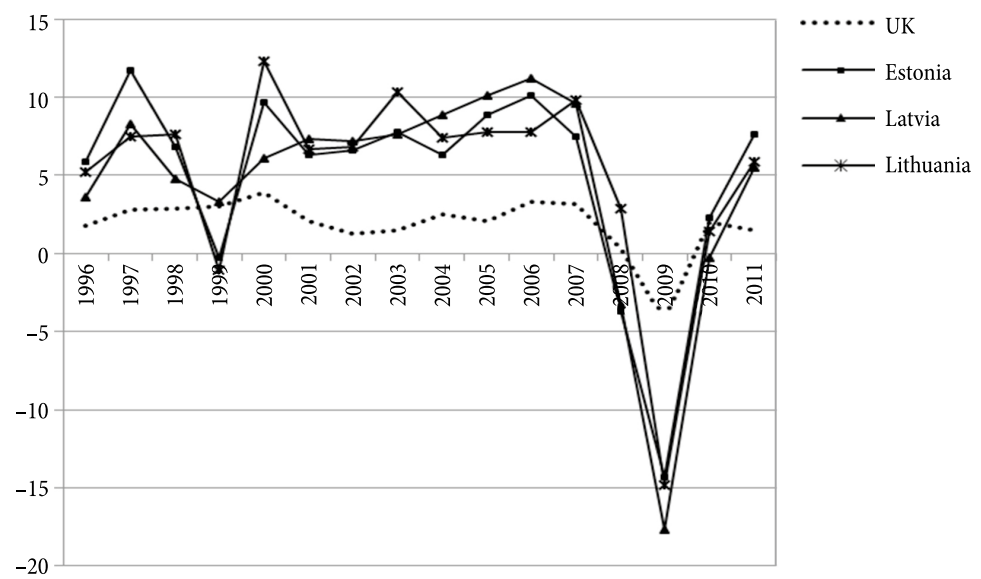

Fig. 2. Real GDP growth rates in the Baltic States and the EU Source: Eurostat (2012).

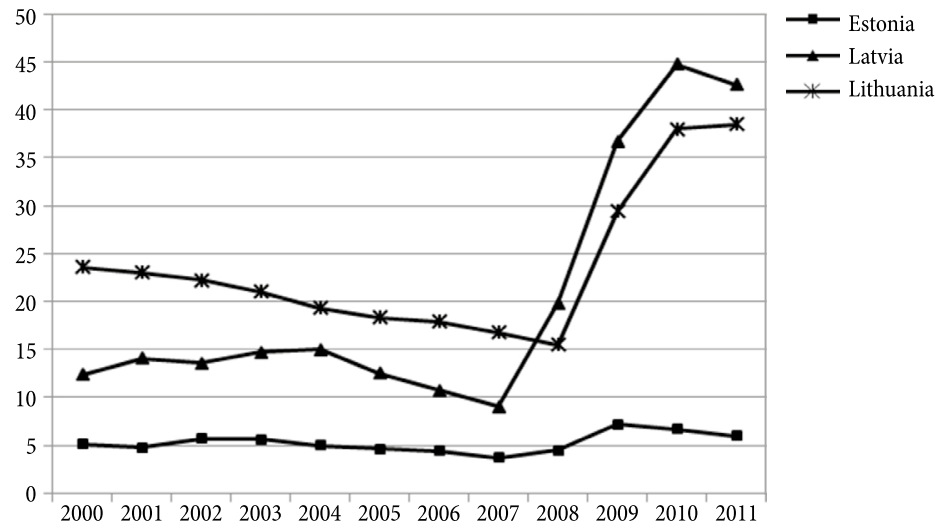

Fig. 3. Government debts in the Baltic States (percentage of GDP) Source: Eurostat (2012). 
a)

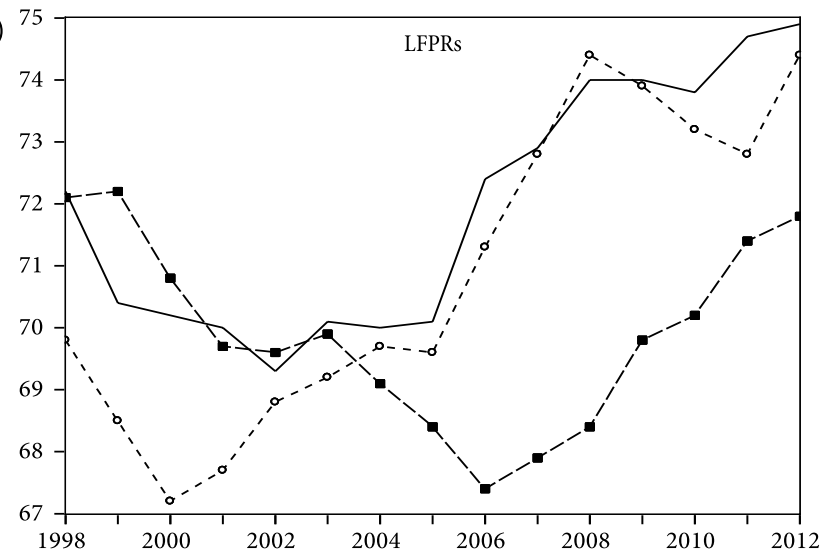

b)

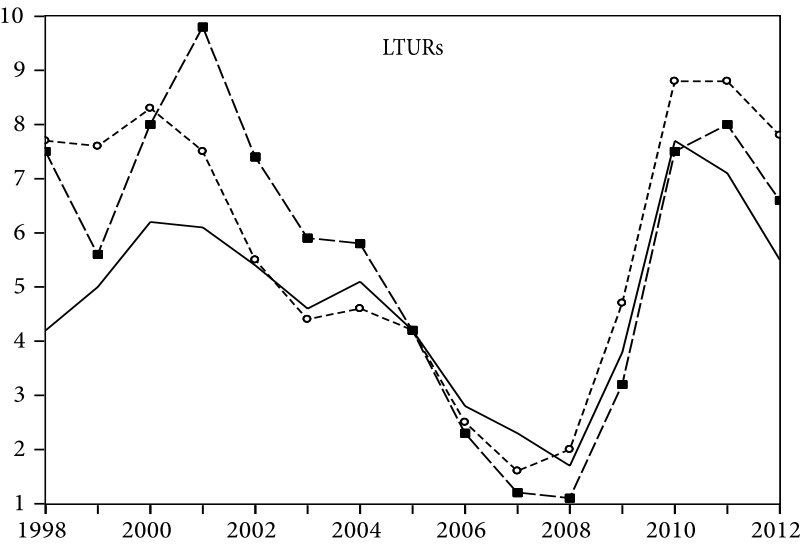

c)

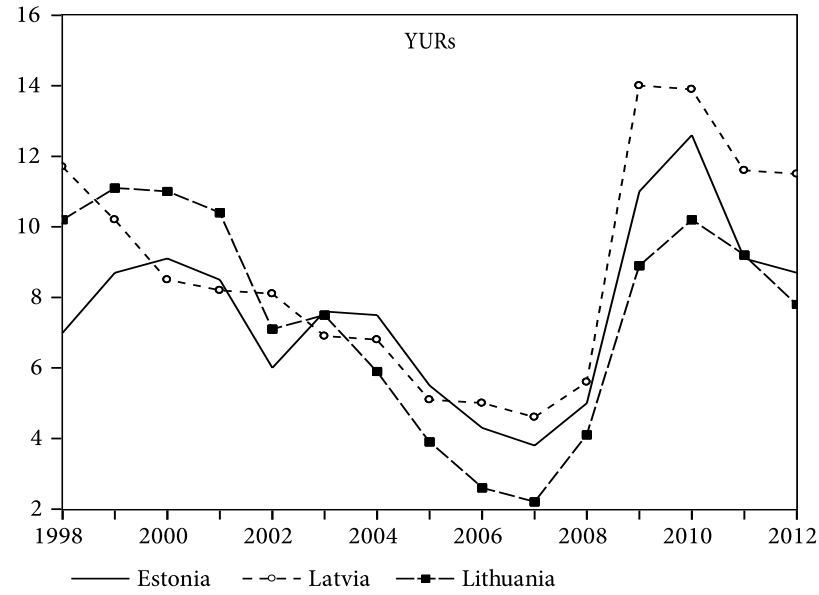

Fig. 4. (a) Labour force participation rates (LRPRs), (b) Long-term unemployment rates (LTURs) and (c) Youth unemployment rates (YURs) Source: Eurostat (2014). 
Figure 4(b) demonstrates the long-term unemployment rates (LTURs) which are defined as the share of the unemployed persons with unemployment period of 12 months or more in the total active population. The LTURs in all three Baltic countries were at their lowest levels in 2007 and 2008, just before the beginning of the economic crisis. As the crisis unravelled, the LTURs rose sharply. Figure 4(c) demonstrates the youth unemployment rates (YURs), which are defined as the share of unemployed youth in the total active young population (i.e., people aged between 15 to 24 years old). Beginning from 2000, the YURs in all three countries were decreasing reaching their lowest levels in 2007. After the advent of the economic crisis, the YUR rose and reached its highest level in 2009 in Latvia and in 2010 in Estonia and Lithuania.

Among the factors that have a considerable impact on the labour market condition are informal economy, gender equality and migration. The informal sector plays an important role in the Baltic countries. According to Schneider et al. (2010), the share of the informal sector was the biggest in Lithuania and the smallest in Latvia. The researchers estimated that approximately one-third of economic activities in Lithuania occurred within the informal sector. Regarding gender equality, a labour force survey among the EU member countries revealed that the situation was relatively good in Lithuania where the male LFPR was 73 percent while female LFPRs was 70 percent, which makes only 3 percent difference. By contrast, gender inequality was relatively high in Estonia where the difference between male and female LFPRs was 7 percent (Eurostat 2014). With regard to migration, in 2012 the share of the foreign born citizens in the total population exceeded 10 percent in Estonia and Latvia. In Lithuania, less than 1 percent of the citizens were foreign born (Eurostat 2014).

\section{Literature review}

Literature on the mean reversion property is abundant. However, the findings of the studies are contradictory (Furuoka 2014). Some researchers found empirical evidence in support of the natural rate hypothesis (Røed 1996; Song, Wu 1998; Camarero, Tamarit 2004; Chang et al. 2005; Christopoulos, León-Ledesma 2007; Romero-Avila, Usabiaga 2007; Lee et al. 2009; Ener, Arica 2011). Others maintained that the hysteresis hypothesis remained valid (Blanchard, Summers 1986a, 1986b; Neudorfer et al. 1990; Brunello 1990; Mitchell 1993; Sephton 2009; Lee et al. 2010; Gomes, da Silva 2008). These contradictions can be due to the differences in the research methods. For example, the analyses based on the univariate unit root tests, such as the ADF test, the Phillips-Perron (PP) test or a modification of these tests failed to reject the null hypothesis of a unit root (Neudorfer et al. 1990; Brunello 1990; Mitchell 1993). On the other hand, the studies that employed the panel methods tended to reject the null hypothesis (Song, Wu 1998; Camarero, Tamarit 2004; Chang et al. 2005; Christopoulos, León-Ledesma 2007). The more recent inquiries incorporating structural breaks and nonlinearity also tended to reject the null hypothesis (e.g., Romero-Avila, Usabiaga 2007; Lee et al. 2009; Ener, Arica 2011) except for the studies by Lee et al. (2010) and Furuoka (2012) who detected the presence of hysteresis in the unemployment rates of Asian countries. 
The available studies on the mean reverting behaviour of the unemployment rates focused, for the most part, on major industrial economies in Europe and North America. A systematic research on this topic in the context of other regions is lacking. One notable exception is a study by Cuestas et al. (2011) who focused on European transition economies including the Baltic countries. A sophisticated econometric technique adopted by the researchers failed to reject the null hypothesis of a unit root. However, according to Cuestas et al. (2011), when nonlinearity was incorporated into the analysis, the null hypothesis of a unit root could be rejected for Estonia and Lithuania. The results of the study provide useful insights into the unemployment rates' linear and nonlinear behaviour.

\section{Methodology and empirical results}

The present study used the quarterly data on unemployment in Estonia, Latvia and Lithuania for the period from 2000Q1 to 2012Q1 (Eurostat 2012). This particular time span was chosen because of the availability of the data for all the three Baltic countries. An important objective of this study was to compare and contrast unemployment dynamics in these countries. Therefore, the number of observations - which was 49 - had to be set according to the common data available, i.e., the data available for each and every of the Baltic countries.

Three unit root tests helped to examine the existence of a unit root in the Baltic countries' unemployment rates. These tests were: (1) the Augmented Dickey-Fuller (ADF) test, (2) the Seemingly Unrelated Regressions Augmented Dickey-Fuller (SURADF) test and (3) the Fourier Augmented Dickey-Fuller (FADF) test. The ADF test was performed based on the following regression (Dickey, Fuller 1979):

$$
\Delta y_{t}=\alpha+\beta y_{t-1}+\sum_{j=1}^{l} \delta_{j} \Delta y_{t-j}+\varepsilon_{t},
$$

where $\alpha, \beta$, and $\delta_{j}$ are the coefficients, $l$ is the lag length of the autoregressive process and $\varepsilon_{t}$ is the error term. The optimal lag length was selected by the Akaike Information Criterion (AIC) (Akaike 1974). The maximum lag length, which was determined by a selection method proposed by Hayashi (2000), was set in this study as 10. Table 1 shows the empirical findings from the ADF tests, which failed to reject the null hypothesis of a unit root in the unemployment rates for all the three Baltic countries. This means that unemployment in these countries could be described as a non-stationary process where the unemployment rates did not seem to have the mean reversion tendency. These findings were confirmed by

Table 1 ADF test results

\begin{tabular}{|c|c|c|c|c|}
\hline \multirow{2}{*}{ Country } & \multirow{2}{*}{$\begin{array}{c}\mathrm{ADF} \\
\text { statistic }\end{array}$} & \multicolumn{3}{|c|}{ Critical values } \\
\hline & & $1 \%$ & $5 \%$ & $10 \%$ \\
\hline Estonia & -2.278 & -3.550 & -2.884 & -2.572 \\
\hline Latvia & -1.324 & -3.547 & -2.858 & -2.540 \\
\hline Lithuania & -2.086 & -3.600 & -2.926 & -2.608 \\
\hline
\end{tabular}

Note: The critical values were obtained by Monte Carlo simulations with 20,000 replications. 
other statistical tests, such as the fractional integration analysis and the persistence analysis (see Appendix).

The SURADF test was performed next. It employed a seemingly unrelated regression (SUR) in combination with the ADF statistics (Breuer et al. 2002). The system of the ADF equations is:

$$
\begin{aligned}
& \Delta y_{1, t}=\alpha_{1}+\left(\rho_{1}-1\right) y_{1, t-1}+\sum_{i=1}^{p} \delta_{i} \Delta y_{2, t-i}+u_{1, t} ; \\
& \Delta y_{2, t}=\alpha_{2}+\left(\rho_{2}-1\right) y_{2, t-1}+\sum_{i=1}^{P} \delta_{i} \Delta y_{2, t-i}+u_{2, t} ; \\
& \Delta y_{N, t}=\alpha_{N}+\left(\rho_{N}-1\right) y_{N, t-1}+\sum_{i=1}^{p} \delta_{i} \Delta y_{n, t-i}+u_{N, t},
\end{aligned}
$$

where $\rho_{i}$ is the autoregressive coefficient for series $i$. In the SURADF procedure, statistical significance of each $\left(\rho_{i}=1\right)$ can be tested. According to Breuer et al. (2002), the SURADF test can examine the null hypothesis of a unit root for each individual panel member. The present study estimated the critical values of the SURADF test by Monte Carlo simulations with 20,000 replications. As Table 2 shows, the SURADF test failed to reject the null hypothesis. This means that unemployment in the Baltic countries could be described as a non-stationary process. These findings endorsed the results obtained from the ADF test.

Table 2. SURADF test results

\begin{tabular}{lcccc}
\hline \multirow{2}{*}{ Country } & SURADF & \multicolumn{3}{c}{ Critical values } \\
\cline { 3 - 5 } & Statistic & 1 percent & 5 percent & 10 percent \\
\hline Estonia & -2.532 & -3.861 & -3.177 & -2.810 \\
\hline Latvia & -1.651 & -4.008 & -3.276 & -2.892 \\
\hline Lithuania & -2.280 & -3.813 & -3.091 & -2.774 \\
\hline
\end{tabular}

Note: The critical values were obtained by Monte Carlo simulations with 20,000 replications.

In the following step of the analysis, the Fourier Augmented Dickey-Fuller (FADF) was performed. Enders and Lee (2012) proposed an ADF-type unit root test that uses a selected frequency component of a Fourier function to capture unknown structural breaks and unattended nonlinearity in the deterministic component of the model. The nonlinear Fourier ADF statistic $\left(\tau_{D F}\right)$ was based on:

$$
y_{t}=\rho y_{t}+c_{0}+\gamma_{1} \sin \left(\frac{2 \pi k t}{T}\right)+\gamma_{2} \cos \left(\frac{2 \pi k t}{T}\right)+\sum_{i=1}^{l} c_{i} \Delta y_{t-i}+e_{t},
$$

where $k$ is the selected frequency for the Fourier approximation, $\gamma$ are the parameters for the trigonometric terms, $t$ is the trend term, $T$ is the number of observations, $\pi=3.1416$. The Fourier ADF statistic $\left(\tau_{D F}\right)$ is the t-statistic for the null hypothesis $\rho=0$ in Equation (3).

The standard ADF test is clearly a special case of the Fourier ADF test in which the trigonometric terms are set as zero (i.e. $\gamma_{1}=\gamma_{2}=0$ ). According to Enders and Lee (2012), the F-statistic can determine whether the trigonometric terms should be included into the 
model. Under the null hypothesis of linearity, the F-statistic can be calculated as:

$$
F(k)=\frac{\left(S S R_{0}-S S R_{1}\right) / q}{S S R_{1}(k) /(T-k)},
$$

where $S S R_{1}$ is the sum of squared residuals (SSR) in Equation (3), $S S R_{0}$ is the SSR from the regression without the trigonometric terms, $q$ is the number of restrictions, and $k$ is the number of regressors in the regression.

As Equation (3) shows, the FADF statistic depends on the frequency and the lag length. Considering that a Fourier function with $k=1$ or $k=2$ can serve as a reasonable approximation to capture many types of unknown structural breaks (Enders, Lee 2012) the maximum frequency $\left(k_{M A X}\right)$ was set in this study as 2 . The optimal frequency is selected by a data-driven method. In the present study, the optimal frequency was the one producing the smallest SSR among the different specifications in Equation (3). The optimal lag length was selected by the AIC while the critical values for the FADF test and the F-test were estimated by Monte Carlo simulations with 20,000 replications. The findings from the FADF tests are reported in Table 3(a), Table 3(b) and Table 3(c).

Table 3(a) contains the findings concerning the optimal frequency and the optimal lag length. The optimal frequencies were set as 1 for all the three Baltic countries; the optimal lag lengths were set as 4 for Estonia and Latvia, and as 9 for Lithuania. Table 3(b) shows the findings from the $F$-test that examined the null hypothesis $\gamma_{1}=\gamma_{2}=0$ in Equation (3). If the null hypothesis of linearity is rejected then the analysis should proceed with the nonlinear unit root test; otherwise, the linear unit root test should be performed. As Table 3(b) shows, the null hypothesis of linearity was rejected for Lithuania only. This means that the nonlinear unit root test - the FADF test - should be used to analyse unemployment in this country. In the cases of Estonia and Latvia, the null hypothesis of linearity could not be rejected; therefore, the linear unit root tests, such as the ADF test and the SURADF test, should be used for the analysis.

Table 3(a). Nonlinear FADF test results (Optimal frequency and lag length)

\begin{tabular}{lllll}
\hline \multicolumn{1}{c}{ Country } & $\tilde{k}$ & SSR & $\tilde{l}$ & AIC \\
\hline Estonia & 1 & 38.390 & 4 & 3.065 \\
\hline Latvia & 1 & 21.249 & 4 & 2.473 \\
\hline Lithuania & 1 & 3.663 & 9 & 1.139 \\
\hline
\end{tabular}

Note: Critical values were estimated by Monte Carlo simulations with 20,000 replications.

Table 3(b). Nonlinear FADF test results (F-statistic)

\begin{tabular}{lcccc}
\hline \multirow{2}{*}{ Country } & \multirow{2}{*}{ F-statistic } & \multicolumn{3}{c}{ Critical values } \\
\cline { 3 - 5 } & & 1 percent & 5 percent & 10 percent \\
\hline Estonia & 4.818 & 13.334 & 9.258 & 7.412 \\
\hline Latvia & 4.366 & 13.334 & 9.258 & 7.412 \\
\hline Lithuania & $18.441^{* * *}$ & 17.214 & 12.206 & 9.994 \\
\hline
\end{tabular}

Note: ${ }^{* * *}$ indicates significance at the $1 \%$ level. Critical values were estimated by Monte Carlo simulations with 20,000 replications. 
Table 3(c). Nonlinear FADF test results (FADF statistic)

\begin{tabular}{lcccc}
\hline \multirow{2}{*}{ Country } & \multirow{2}{*}{ FADF statistic } & \multicolumn{3}{c}{ Critical values } \\
\cline { 3 - 5 } & & 1 percent & 5 percent & 10 percent \\
\hline Estonia & $-3.954^{* *}$ & -4.672 & -3.899 & -3.512 \\
\hline Latvia & -2.597 & -4.672 & -3.899 & -3.512 \\
\hline Lithuania & $-4.658^{* * *}$ & -4.631 & -3.849 & -3.475 \\
\hline
\end{tabular}

Note: ${ }^{* * *}$ indicates significance at the $1 \%$ level; ${ }^{* *}$ indicates significance at the $5 \%$ level. Critical values were estimated by Monte Carlo simulations with 20,000 replications.

As the results indicated, the ADF test and the SURADF test did not reject the null hypothesis of a unit root in Estonia's and Latvia's unemployment rates. These findings indicate that unemployment in these countries could be best described as a non-stationary process in accordance with the hysteresis hypothesis. More importantly, as Table 3(c) shows, the nonlinear FADF test did reject the null hypothesis of a unit root in Lithuania's unemployment rate. This means that unemployment in this country could be described as a stationary process in accordance with the natural rate hypothesis.

Additional econometric tests were performed in order to confirm the findings obtained from the nonlinear FADF test. Among them were the unit root tests with structural breaks and the Ng-Perron (NP) unit root tests. Also, in order to take account of one structural break the PV test (Perron, Vogelsang 1992) was carried out. In the first step, the PV test was based on:

$$
y_{t}=\mu+\delta D U_{t}+\tilde{y}
$$

where $y_{t}$ is the variable of interest, $D U_{t}=1$ if $t>T B$ and 0 otherwise; TB is the breakpoint, $\mu$ is the constant and $\delta$ is the slope coefficient. The second step of the PV test was based on:

$$
\tilde{y}_{t}=\sum_{i=0}^{k} \omega_{i} D T B_{t-i}+\alpha \tilde{y}_{t-1}+\sum_{i=1}^{k} c_{i} \Delta \tilde{y}_{t-i}+e_{t}
$$

where $D T B_{t}=1$ if $t=T B+1$ and 0 otherwise; $\omega, \alpha$ and $c$ are the slope coefficients, $e_{t}$ is the error term and $k$ is the truncation lag parameter. As the findings shown in Table 4(a) indicate, the unemployment rates in the Baltic countries could be described as a nonstationary process, even after the estimation model had taken account of a structural break in the long-run mean value.

Clemente et al. (1998) extended the PV method to the cases with two structural breaks in the long-run mean value. The first step of the Clemente-Montañés-Reyes (CMR) test was based on:

$$
y_{t}=\mu+\delta_{1} D U_{1 t}+\delta_{2} D U_{2 t}+\tilde{y}
$$

where $D U_{i t}=1$ if $t>T B_{i}(i=1,2)$ and 0 otherwise. The second step of the CMR test was based on:

$$
\tilde{y}_{t}=\sum_{i=0}^{k} \omega_{1 i} D T B_{1 t-i}+\sum_{i=0}^{k} \omega_{2 i} D T B_{2 t-i}+\alpha \tilde{y}_{t-1}+\sum_{i=1}^{k} c_{i} \Delta \tilde{y}_{t-i}+e_{t},
$$

where $D T B_{i t}=1$ if $t=T B_{i}+1(i=1,2)$ and 0 otherwise. The findings from the CMR test are presented in Table 4(b). They show that the unemployment rate in the Baltic countries could be characterised as a unit root process even after the estimation model had taken ac- 
count of two structural breaks. Furthermore, this study performed the one-break Lagrange Multiplier (LM) unit root test (Lee, Strazicich 2004) and the two-break LM unit root test (Lee, Strazicich 2003). These LM methods are able to allow for structural breaks under the null and the alternative hypotheses. The one-break LM unit root test was based on:

$$
\Delta y_{t}=\delta^{\prime} \Delta Z_{t}+\phi \tilde{S}_{t-1}+\sum_{i=1}^{k} \gamma_{i} \Delta \tilde{S}_{t-i}+u_{t},
$$

where $y_{t}$ is the variable of interest, $\delta, \phi$ and $\gamma$ are the slop coefficients, $Z_{t}$ is the vector of the exogenous variables, $\tilde{S}$ is the "detrended" variable and $k$ is the number of optimal lag lengths. Table 4(c) reports the findings from the one-break LM test, which indicated that the unemployment rates in all three Baltic countries were nonstationary. This means that unemployment in the region could be seen as a unit root process after the estimation model had taken account of one structural break. The findings from the two-break LM test are shown in Table 4(d). They indicated that the unemployment rate in Lithuania was stationary while the unemployment rates in Estonia and Latvia were nonstationary.

Table 4(a). PV test results

\begin{tabular}{lccc}
\hline \multicolumn{1}{c}{ Country } & Breakpoint & PV statistic & 5\% critical value \\
\hline Estonia & $2009 \mathrm{Q} 3$ & -2.447 & -3.65 \\
\hline Latvia & $2010 \mathrm{Q} 1$ & -2.247 & -3.65 \\
\hline Lithuania & $2006 \mathrm{Q} 2$ & -2.438 & -3.65 \\
\hline
\end{tabular}

Note: The critical values were obtained from Perron and Vogelsang (1992).

Table 4(b). CMR test results

\begin{tabular}{lccc}
\hline \multicolumn{1}{c}{ Country } & Breakpoints & CMR statistic & 5\% critical value \\
\hline Estonia & 2004Q3/2009Q3 & -3.606 & -5.70 \\
\hline Latvia & 2004Q1/2009Q3 & -3.991 & -5.70 \\
\hline Lithuania & 2004Q4/2009Q3 & -2.257 & -5.70 \\
\hline
\end{tabular}

Note: The critical values were obtained from Clemente et al. (1998).

Table 4(c). One-break LM test results

\begin{tabular}{lccc}
\hline \multicolumn{1}{c}{ Country } & Breakpoint & LM statistic & 5\% critical value \\
\hline Estonia & $2010 \mathrm{Q} 4$ & -2.543 & -3.56 \\
\hline Latvia & $2008 \mathrm{Q} 4$ & -3.000 & -3.56 \\
\hline Lithuania & $2008 \mathrm{Q} 3$ & -3.427 & -3.56 \\
\hline
\end{tabular}

Note: The critical values were obtained from Lee and Strazicich (2004).

Table 4(d). Two-break LM test results

\begin{tabular}{lccc}
\hline \multicolumn{1}{c}{ Country } & Breakpoint & LM statistic & 5\% critical value \\
\hline Estonia & 2009Q4/2010Q4 & -2.870 & -3.84 \\
\hline Latvia & 2002Q4/2010Q4 & -3.194 & -3.84 \\
\hline Lithuania & 2002Q1/2008Q3 & $-3.935^{\star}$ & -3.84 \\
\hline
\end{tabular}

Notes: * indicates significance at the $5 \%$ level. The critical values were obtained from Lee and Strazicich (2003). 
Considering that the actual trending patterns of unemployment dynamics in the region could be indicative of the presence of more than two structural breaks (Camarero et al. 2005) this study performed the multiple structural break test suggested by Bai and Perron (1998). Table 5 reports the findings from this test, which showed that the Bayesian information criterion (BIC) increased with the growing number of structural breaks in all the three Baltic countries. This means that the actual trending pattern of unemployment dynamics in the region did not seem to be indicative of the presence of more than two structural breaks.

Table 5. BP test results

\begin{tabular}{lcccc}
\hline Country & 1 Breakpoint & 2 Breakpoints & 3 Breakpoints & 4 Breakpoints \\
\hline Estonia & $2010 \mathrm{Q} 1$ & 2007Q3/2010Q1 & 2005Q1/2007Q3/2010Q1 & $\begin{array}{c}\text { 2002Q3/2005Q1/ } \\
\text { 2007Q3/2010Q1 }\end{array}$ \\
\hline BIC & $13.601^{*}$ & 13.813 & 14.023 & 14.230 \\
\hline Latvia & $2001 \mathrm{Q} 4$ & 2001Q4/2004Q2 & 2001Q4/2004Q2/2006Q4 & $\begin{array}{c}\text { 2001Q4/2004Q2/ } \\
\text { 2006Q4/2009Q2 }\end{array}$ \\
\hline BIC & $13.601^{\star}$ & 13.814 & 14.025 & 14.231 \\
\hline Lithuania & $2009 \mathrm{Q} 3$ & $2007 \mathrm{Q} 1 / 2009 \mathrm{Q} 3$ & $2004 \mathrm{Q} 3 / 2007 \mathrm{Q} 1 / 2009 \mathrm{Q} 3$ & $\begin{array}{c}2002 \mathrm{Q} 1 / 2004 \mathrm{Q} / \\
2007 \mathrm{Q} 1 / 2009 \mathrm{Q} 3\end{array}$ \\
\hline BIC & $13.590^{*}$ & 13.802 & 14.011 & 14.211 \\
\hline
\end{tabular}

Note: ${ }^{*}$ indicates the lowest Bayesian Information Criterion (BIC) values among four different types of structural breaks.

Furthermore, the Ng-Perron (NP) unit root test (Ng, Perron 2001) was performed because the limited number of observations in the unemployment dataset could cause the small sample problem. The NP test has a better small sample performance because it is based on the generalized least squares (GLS) detrending procedure (Camarero et al. 2005). The findings from the NP test (see Table 6) indicated that the unemployment rates in Estonia and Lithuania - but not in Latvia - could be considered as a stationary process.

Table 6. NP test results

\begin{tabular}{lcccc}
\hline \multicolumn{1}{c}{ Country } & $\mathrm{MZ}_{\alpha}$ & $\mathrm{MZ}_{t}$ & $\mathrm{MSB}$ & $\mathrm{MP}_{t}$ \\
\hline Estonia & $-9.735^{\star *}$ & $-2.202^{* *}$ & $0.266^{* *}$ & $2.530^{\star *}$ \\
\hline Latvia & -5.302 & -1.612 & 0.304 & 4.663 \\
\hline Lithuania & $-5.801^{\star}$ & $-1.703^{\star}$ & 0.293 & $4.223^{\star}$ \\
\hline
\end{tabular}

Note: ${ }^{*}$ indicates significance at the $5 \%$ level; ${ }^{\star}$ indicates significance at the $10 \%$ level.

Overall, the results obtained from the unit root tests with structural breaks and the NP test were in line with the findings from the nonlinear FADF test. In other words, unemployment in Lithuania could be considered as a stationary process when the appropriate unit root tests were performed, which included the LM unit root test with two structural breaks and the NP unit root test. On the other hand, despite some minor discrepancies in the results unemployment in Estonia and Latvia could be considered as a nonstationary process. 
In the final step of the analysis this study estimated the power and size of each of the three unit root tests using the method suggested by Dickey and Fuller (1979). Two different levels of significance - 0.05 and 0.10 - were selected and Monte Carlo simulations with 20,000 replications were carried out. Table 7(a) and Table 7(b) show the empirical results. As Table 7(a) demonstrates, all three tests had similar power and size to test the null hypothesis at the two-tailed significance level of 0.05 . In the cases of Estonia and Latvia, the ADF test led to a slightly better size than the other two methods. The SURADF test seemed to have a better size property for Lithuania. Table 7(b) shows that the three tests had similar power and size to test the null hypothesis at the two-tailed significance level of 0.10 . More

Table 7(a). Power and size of the two-tailed 0.05 test $(\rho=1)$

\begin{tabular}{lccccccc}
\hline \multirow{2}{*}{ Estonia } & \multicolumn{7}{c}{$\rho$} \\
\cline { 2 - 8 } & 0.80 & 0.90 & 0.95 & 0.99 & 1.00 & 1.02 & 1.05 \\
\hline ADF & 0.215 & 0.097 & 0.070 & 0.049 & 0.055 & 0.034 & 0.010 \\
\hline SURADF & 0.197 & 0.092 & 0.065 & 0.055 & 0.048 & 0.028 & 0.009 \\
\hline FADF & 0.094 & 0.071 & 0.059 & 0.053 & 0.046 & 0.032 & 0.010 \\
\hline \multirow{2}{*}{ Latvia } & \multicolumn{7}{c}{$\rho$} \\
\cline { 2 - 8 } & 0.80 & 0.90 & 0.95 & 0.99 & 1.00 & 1.02 & 1.05 \\
\hline ADF & 0.157 & 0.087 & 0.064 & 0.055 & 0.050 & 0.031 & 0.010 \\
\hline SURADF & 0.147 & 0.083 & 0.064 & 0.054 & 0.051 & 0.032 & 0.011 \\
\hline FADF & 0.094 & 0.071 & 0.059 & 0.053 & 0.046 & 0.032 & 0.010 \\
\hline \multirow{2}{*}{ Lithuania } & 0.80 & 0.90 & 0.95 & 0.99 & 1.00 & 1.02 & 1.05 \\
\cline { 2 - 9 } & 0.262 & 0.111 & 0.070 & 0.052 & 0.049 & 0.031 & 0.011 \\
\hline ADF & 0.268 & 0.111 & 0.074 & 0.059 & 0.052 & 0.033 & 0.009 \\
\hline SURADF & 0.066 & 0.065 & 0.063 & 0.050 & 0.051 & 0.036 & 0.012 \\
\hline FADF & & & & & & &
\end{tabular}

Table 7(b). Power and Size of the two-tailed 0.10 test $(\rho=1)$

\begin{tabular}{lccccccc}
\hline \multirow{2}{*}{ Estonia } & \multicolumn{7}{c}{$\rho$} \\
\cline { 2 - 8 } & 0.80 & 0.90 & 0.95 & 0.99 & 1.00 & 1.02 & 1.05 \\
\hline ADF & 0.355 & 0.181 & 0.130 & 0.106 & 0.095 & 0.059 & 0.017 \\
\hline SURADF & 0.351 & 0.188 & 0.135 & 0.113 & 0.099 & 0.069 & 0.018 \\
\hline FADF & 0.181 & 0.147 & 0.128 & 0.105 & 0.095 & 0.065 & 0.021 \\
\hline \multirow{2}{*}{ Latvia } & 0.80 & 0.90 & 0.95 & 0.99 & 1.00 & 1.02 & 1.05 \\
\cline { 2 - 8 } & 0.268 & 0.163 & 0.121 & 0.108 & 0.095 & 0.064 & 0.015 \\
\hline ADF & 0.264 & 0.165 & 0.122 & 0.106 & 0.098 & 0.066 & 0.017 \\
\hline SURADF & 0.181 & 0.147 & 0.128 & 0.105 & 0.095 & 0.065 & 0.021 \\
\hline FADF & & & & $\rho$ & & & \\
\hline \multirow{2}{*}{ Lithuania } & 0.80 & 0.90 & 0.95 & 0.99 & 1.00 & 1.02 & 1.05 \\
\hline ADF & 0.416 & 0.195 & 0.132 & 0.109 & 0.095 & 0.067 & 0.017 \\
\hline SURADF & 0.419 & 0.149 & 0.141 & 0.111 & 0.101 & 0.065 & 0.019 \\
\hline FADF & 0.133 & 0.130 & 0.125 & 0.113 & 0.099 & 0.077 & 0.023 \\
\hline
\end{tabular}

Note: Power and size values were estimated by Monte Carlo simulations with 20,000 replications. 
precisely, for Estonia and Lithuania the SURADF test seemed to ensure a slightly better power compared to the other two tests; the ADF test offered a slightly better size for Latvia. This means that despite the above-mentioned nuances the three tests were equally robust and efficient and had the similar power and size at the 0.10 and 0.05 levels of significance.

In short, the results of the ADF test and the SURADF test indicated that the unemployment rates in the Baltic countries could be described as a non-stationary process. This finding supports the hysteresis hypothesis. However, the empirical findings from the recently developed and more powerful nonlinear FADF test indicated that Lithuania's unemployment rate could be described as a stationary process in line with the natural rate hypothesis. These results demonstrate that mean reversion in unemployment can be captured only when a study performs the appropriate nonlinear unit root tests.

\section{Conclusions}

The findings of this study revealed that only in Lithuania unemployment could be described as a stationary process. This means that the unemployment rate in this country had a tendency to revert to the equilibrium level, which lends support to the natural rate hypothesis. On the other hand, unemployment in Estonia and Latvia could be best described as a non-stationary process in accordance with the hysteresis hypothesis. In other words, Estonia's and Latvia's unemployment rates did not show signs of the mean reverting behaviour.

These findings are largely in agreement with the results reported by Cuestas et al. (2011) who examined the unemployment rates in the Baltic countries as a part of their analysis of unemployment dynamics in transition European economies. The researchers argued that, without taking account of nonlinearity, the unemployment rates in all the three Baltic countries could be considered as a unit root process. The current analysis produced similar results. Cuestas et al. (2011) also found that there was no structural break in the Baltic countries' unemployment time-series, except for Lithuania. The current study supported this finding. Furthermore, in Cuestas' et al. (2011) study the nonlinear unit root test rejected the null hypothesis of a unit root for Estonia and Lithuania but failed to reject it in the case of Latvia. The present study obtained the same results for Latvia and Lithuania. However, in the case of Estonia, there were some discrepancies in the findings. The differences in the results could be due to the differences in the research methods adopted by the two studies. In the present analysis, the nonlinear FADF test rejected the null hypothesis of a unit root (see Table 3(c)), which indicated that unemployment in Estonia could be described as a stationary process. However, the F-test was unable to reject the null hypothesis of nonlinearity (see Table 3(b)). This indicated that the ADF test, rather than the FADF test, could be a more suitable procedure to examine unemployment dynamics in Estonia.

It is not an easy task to pinpoint the factors accountable for the diverging paths of unemployment dynamics in the Baltic countries. However, three aspects could have contributed to the differences in the movements of the Baltic countries' unemployment rates, which are: (1) the disparities in the levels of the Baltic countries' financial sector development; 
(2) the differences in their labour markets conditions, and (3) the differences in the size of the informal sector. First of all, Lithuania's financial sector was less developed compared to Estonia's and Latvia's. As a result, Lithuania was spared a tremendous negative impact of the global financial crisis on employment in the country's banking and financial services industry. Financial sectors in Latvia and Estonia, on the other hand, had experienced more severe and long-lasting consequences of the crisis. Secondly, in terms of gender equality Lithuania's labour market was in a better condition compared to its Baltic neighbours. A good gender balance in the labour market cushioned the negative impact of the economic shock on Lithuania's employment situation. This means that if one of the working spouses had lost job in a market production sector the person could be absorbed into a non-market home production sector. Thirdly, regarding the informal sector, Lithuania had a large informal economy and a substantial informal employment sector. Therefore, it is reasonable to suggest that in the case of Lithuania a relatively large informal sector contributed to a smoother transition of the unemployment path by absorbing the workers who had lost employment in the formal sector.

Generally, in the countries where the informal sector is small the economic downturn would have more pronounced and severe negative impacts on the employment situation. This assumption can be translated into a hypothesis that the t-statistic for the autoregressive parameter would be lower in a country with a large informal sector. In other words, the share of the informal sector in the total output is hypothesised to have a negative association with the FADF statistic. This hypothesis was tested using the data on the unemployment rates in nine EU countries located in Central and East Europe (i.e., Bulgaria, Estonia, Croatia, Latvia, Lithuania, Hungary, Poland, Romania and Slovenia) for the period from 2001Q1 to 2012Q4 (Eurostat 2014) and the data on the share of the informal sector compiled by Schneider et al. (2010). Figure 5 depicts the relationship between the black market share (BMS) and the FADF statistic. Despite some minor discrepancies, the results indicated a negative association between the BMS and the FADF statistic.

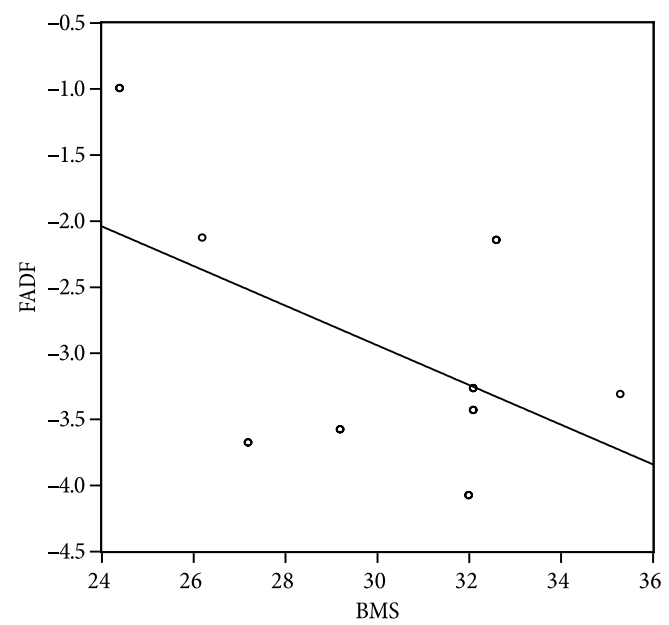

Fig. 5. Relationship between black market share (BMS) and FADF statistic 
Several important policy implications could be drawn from the findings of the present study. The empirical results suggest that the higher-than-normal unemployment rates in Estonia and Latvia lacked the mean reverting behaviour and, therefore, were not likely to revert to the natural level of unemployment. This means that policymakers in these countries would need to hammer out effective programs in order to efficiently deal with the problem of high unemployment. As one of the measures, the governments in Estonia and Latvia may want to promote comprehensive and systematic policies aimed at economic liberalization and deregulation in order to attract more FDIs. In the case of Lithuania, as the findings suggest, the higher-than-normal unemployment rate had a tendency to return to the natural rate of unemployment. Therefore, policymakers in the country may want to focus on the long-run strategies aimed at strengthening the labour market fundamentals. Furthermore, contractionary fiscal policies in Estonia and Latvia aimed at achieving the EU's criteria on the budgetary deficit ceiling (the debt-to-GDP ratio) can produce negative and long-lasting impacts on the unemployment rates in these countries. The Lithuanian government, on the other hand, has a wider choice of policy options to fulfil the EU's criteria. Finally, in the cases of Estonia and Latvia, restrictive monetary policies aimed at controlling inflation in order to meet the European Central Bank's target inflation rate could worsen the situation with unemployment. Therefore, policymakers in these countries may want to decide against reducing money supply in order to push down the inflation rate. By contrast, the Lithuanian government can have a wider range of options to regulate money supply in order to achieve the target inflation rate.

The present study examined and compared the behaviour of the unemployment rates in Latvia, Estonia and Lithuania over the period from 2000Q1 to 2012Q2. It used for this purpose the data on unemployment available in the Eurostat database. This imposed some limitations in the implementation of the analysis especially concerning the time span that excluded the pre-2000 period. In the Eurostat database the observations for the pre-2000 period are available only for Latvia (1998Q2 - 1999Q4) and Lithuania (1998Q1 - 1999Q4) and are missing for Estonia. Future studies on this topic may want to use alternative sources of data with more observations in the time series.

This study proposed some factors that could have a strong impact on the paths of the unemployment rates in the Baltic countries. A systematic analysis of the relationship between these factors and unemployment dynamics could be an interesting topic for further studies. These studies could estimate the t-statistic for the autoregressive parameters first and then proceed to identify the elements that have a significant impact on these statistics. More importantly, as econometrics and statistics experts have suggested (Camarero et al. 2006; Christopoulos, León-Ledesma 2010; Cuestas et al. 2011), researchers need to use the latest available statistical procedures to examine the stationary process of the time series data. The findings of such studies would give much needed insights on the mean reverting behaviour of the unemployment rates. A better understanding of unemployment dynamics would allow generating more effective policies to deal with the problem of high unemployment in the Baltic countries and beyond. 


\section{References}

Akaike, H. 1974. A new look at the statistical identification, IEEE Transactions on Automatic Control 19(6): 716-723. http://dx.doi.org/10.1109/TAC.1974.1100705

Bai, J.; Perron, P. 1998. Estimating and testing linear models with multiple structural changes, Econometrica 66(1): 47-78. http://dx.doi.org/10.2307/2998540

Blanchard, O. J.; Summers, L. H. 1986a. Hysteresis in unemployment, NBER Working Paper 2035. Cambridge, MA: National Bureau of Economic Research. 14 p. http://dx.doi.org/10.3386/w2035

Blanchard, O. J.; Summers, L. H. 1986b. Hysteresis and the European unemployment problem, NBER Working Paper 1950. Cambridge, MA: National Bureau of Economic Research. 78 p. http://dx.doi.org/10.3386/w1950

Breuer, J. B.; McNown, R.; Wallace, M. 2002. Series-specific unit root tests with panel data, Oxford Bulletin of Economics and Statistics 64(5): 527-546. http://dx.doi.org/10.1111/1468-0084.00276

Brunello, G. 1990. Hysteresis and “The Japanese unemployment problem": a preliminary investigation, Oxford Economic Papers 42(3): 483-500.

Camarero, M.; Carrion-i-Silvestre, J. L.; Tamarit, C. 2005. Unemployment dynamics and NAIRU estimates for accession countries: a univariate approach, Journal of Comparative Economics 33(3): 584-603. http://dx.doi.org/10.1016/j.jce.2005.04.001

Camarero, M.; Carrion-i-Silvestre, J. L.; Tamarit, C. 2006. Testing for hysteresis in unemployment in OECD countries: new evidence using stationarity panel tests with breaks, Oxford Bulletin of Economics and Statistics 68(2): 167-182 http://dx.doi.org/10.1111/j.1468-0084.2006.00157.x

Camarero, M.; Tamarit, C. 2004. Hysteresis vs. natural rate of unemployment: new evidence for OECD countries, Economics Letters 84(3): 413-417. http://dx.doi.org/10.1016/j.econlet.2004.02.014

Chang, T.; Lee, K. C.; Nieh, C. C.; Wei, C. C. 2005. An empirical note on testing hysteresis in unemployment for ten European countries: panel SURADF approach, Applied Economics Letters 12(14): 881-886. http://dx.doi.org/10.1080/13504850500365871

Christopoulos, D. K.; León-Ledesma, M. A. 2007. Unemployment hysteresis in EU countries: what do we really know about it?, Journal of Economic Studies 34(2): 80-89. http://dx.doi. org/10.1108/01443580710745353

Christopoulos, D. K.; León-Ledesma, M. A. 2010. Smooth break and non-linear mean reversion: postBretton Woods real exchange rates, Journal of International Monetary and Finance 29(6): 10761093. http://dx.doi.org/10.1016/j.jimonfin.2010.02.003

Clemente, J.; Montañés, A.; Reyes, M. 1998. Testing for a unit root in variables with a double change in the mean, Economics Letters 59(2): 175-182. http://dx.doi.org/10.1016/S0165-1765(98)00052-4

Cochrane, J. H. 1988. How big is the random walk in GNP?, Journal of Political Economy 96(5): 893-920.

Cuestas, J. C.; Gil-Alana, L. A.; Staehr, K. 2011. A further investigation of unemployment persistence in European transition economies, Journal of Comparative Economics 39(4): 514-532. http://dx.doi. org/10.1016/j.jce.2011.09.002

DeLong, B. 2011. Forecasting the unemployment rate [online], [cited 17 March 2014]. Available from Internet: http://delong.typepad.com/sdj/2011/07/forecasting-the-unemployment-rate.html

Dickey, P. A.; Fuller, W. A. 1979. Distribution of the estimators for autoregressive time-series with a unit root, Journal of American Statistical Association 74(366): 427-431. http://dx.doi.org/10.2307/2286348

Diebold, F. X.; Rudebusch, G. D. 1989. Long memory and persistence in aggregate output, Journal of Monetary Economics 24(2): 189-209. http://dx.doi.org/10.1016/0304-3932(89)90003-2

Enders, W.; Lee, J. 2012. The flexible Fourier form and the Dickey-Fuller type unit root tests, Economics Letters 117(1): 196-199. http://dx.doi.org/10.1016/j.econlet.2012.04.081 
Ener, M.; Arica, F. 2011. Is there hysteresis in unemployment in OECD countries? Evidence from panel unit root test with structural breaks, Chinese Business Review 10(4): 294-304.

Eurostat. 2012. Database by themes [online], [cited 30 June 2012]. Available from Internet: http://epp. eurostat.ec.europa.eu/portal/page/portal/statistics/search_database

Eurostat. 2014. Population and social conditions [online], [cited 30 June 2012]. Available from Internet: http://epp.eurostat.ec.europa.eu/portal/page/portal/statistics/search_database

Friedman, M. 1968. The role of monetary policy, American Economic Review 58(1): 1-17.

Furuoka, F. 2012. Unemployment hysteresis in the East Asia-Pacific region: new evidence from MADF and SURADF tests, Asian-Pacific Economic Literature 26(2): 133-143. http://dx.doi.org/10.1111/j.1467-8411.2012.01351.x

Furuoka, F. 2014. Does hysteresis exist in unemployment? New findings from fourteen regions of the Czech Republic, Czech Journal of Economics and Finance 64(1): 59-78.

Geweke, J.; Porter-Hudak, S. 1983. Estimation and application of long-memory time series, Journal of Time Series Analysis 4(4): 221-238. http://dx.doi.org/10.1111/j.1467-9892.1983.tb00371.x

Gomes, F.; da Silva, C. G. 2008. Hysteresis vs. natural rate of unemployment in Brazil and Chile, Applied Economics Letters 15(1): 53-56. http://dx.doi.org/10.1080/13504850600675450

Gregory, R. 1986. Wages policy and unemployment in Australia, Economica 53(210): S53-S74. http://dx.doi.org/10.2307/2554374

Gustavsson, M.; Osterholm, P. 2011. Hysteresis in the US unemployment rate - evidence from bootstrapped out-of-sample forecasts, Applied Economics Letters 18(7): 643-646. http://dx.doi. org/10.1080/13504851003761855

Hannay, C. 2011. Estonia's star shines in debt crisis - but for how long?, The Globe and Mail, 14 November [online], [cited 30 June 2012]. Available from Internet: http://www.theglobeandmail.com/

Hayashi, F. 2000. Econometrics. Princeton University Press. 690 p.

Lee, H. Y.; Wu, J. L.; Lin, C. H. 2010. Hysteresis in East Asian unemployment, Applied Economics 42(7): 887-898. http://dx.doi.org/10.1080/00036840701720895

Lee, J.; Strazicich, M. C. 2003. Minimum Lagrange multiplier unit root test with two structural breaks, Review of Economics and Statistics 85(4): 1082-1089.

Lee, J.; Strazicich, M. C. 2004. Minimum LM unit root test with one structural break, Working Paper 04-17, Department of Economics, Appalachian State University. 16 p.

Lee, J. D.; Lee, C. C.; Chang, C. P. 2009. Hysteresis in unemployment revisited: evidence from panel LM unit root tests with heterogeneous structural breaks, Bulletin of Economic Research 61(4): 325-334. http://dx.doi.org/10.1111/j.1467-8586.2008.00287.x

Matthews, G. 2007. The Baltic Tigers, Baltic special report, July/August, 2007 [online], [cited 30 June 2012]. Available from Internet: http://capacityconferences.com

Miškinis, A.; Reinbold, B. 2010. Investments of German MNEs into production networks in Central European and Baltic States, Ukio Technologinis ir Ekonominis Vystymas 16(4): 717-735. http://dx.doi. org/10.3846/tede.2010.44

Mitchell, W. F. 1993. Testing for unit roots and persistence in OECD unemployment rates, Applied Economics 25(12): 1489-1501. http://dx.doi.org/10.1080/00036849300000153

Neudorfer, P.; Pichelmann K.; Wagner, M. 1990. Hysteresis, Nairu and long term unemployment in Austria, Empirical Economics 15(2): 217-229. http://dx.doi.org/10.1007/BF01973454

Ng, S.; Perron, P. 2001. Lag length selection and the construction of unit root tests with good size and power, Econometrica 69(6): 1519-1554.

Perron, P.; Vogelsang, T. 1992. Nonstationarity and level shifts with an application to purchasing power parity, Journal of Business and Economic Statistics 10(3): 301-320.

http://dx.doi.org/10.1080/07350015.1992.10509907 
Phelps, E. S. 1967. Phillips curves, expectations of inflation and optimal unemployment over time, Economica 34(135): 254-281. http://dx.doi.org/10.2307/2552025

Røed, K. 1996. Unemployment hysteresis - macro evidence from 16 OECD countries, Empirical Economics 21(4): 589-600. http://dx.doi.org/10.1007/BF01180703

Romero-Avila, D.; Usabiaga, C. 2007. Unit root tests, persistence and the unemployment rates in the US states, Southern Economic Journal 73(3): 698-716. http://dx.doi.org/10.2307/20111919

Schneider, F.; Buehn, A.; Montenegro, C. 2010. Shadow economies all over the world: new estimates for 162 countries from 1999 to 2007, Policy Research Working Paper 5356. World Bank, Washington, DC. $54 \mathrm{p}$.

Sephton, P. S. 2009. Persistence in the US state unemployment rates, Southern Economic Journal 76(2): 458-466. http://dx.doi.org/10.4284/sej.2009.76.2.458

Song, F. M.; Wu, Y. 1998. Hysteresis in unemployment: evidence from OECD countries, The Quarterly Review of Economics and Finance 38(2): 181-191. http://dx.doi.org/10.1016/S1062-9769(99)80111-2

The Economist. 2010. The best Balt will be Nordic [online], [cited 30 June 2012]. Available from Internet: http://www.economist.com/blogs/theworldin2012

Wang, P. 2009. Financial econometrics. $2^{\text {nd }}$ ed. Taylor and Francis. 320 p.

\section{APPENDIX}

\section{Additional econometric analyses}

The fractional integration analysis and the persistence analysis were performed to confirm the findings from the linear ADF tests. The fractional integration method was used to estimate the fractional differencing parameter $(d)$ in the unemployment time series (Geweke, Porter-Hudak 1983). The autoregressive fractionally integrated moving average (ARFIMA) model estimated the fractional differencing parameter by incorporating the fractional integrating parameter to the autoregressive moving average (ARMA) model. The ARFIMA $(p, d, q)$ model was based on the equation (Diebold, Rudebusch 1989):

$$
\Phi(L)(1-L)^{d} y_{t}=\Theta(L),
$$

where $y_{t}$ is the variable of interest, $L$ is the lag operator and $d$ is the fractional differencing parameter. The autoregressive polynomial $\Phi(L)$ of the degree $p$ can be expressed as $\Phi(L)=1-\varphi_{1} L-\ldots . .-\varphi_{p} L^{p}$ and the moving average polynomial $\Theta(L)$ of the degree $q$ is expressed as $\Theta(L)=1-\theta_{1} L-\ldots . .-\theta_{q} L^{q}$. Equation (A1) can be reformulated:

$$
(1-L)^{d} y_{t}=\Phi^{-1}(L) \Theta(L) \equiv u_{t} .
$$

The estimation of the fractional differencing parameter, $d$, was based on:

$$
\ln \left\{I\left(\lambda_{j}\right)\right\}=\beta_{0}+\beta_{1} \ln \left\{4 \sin ^{2}\left(\lambda_{j} / 2\right)\right\}+\eta_{j}, j=0 \ldots . T^{1 / 2},
$$

where $\beta_{0}$ is the constant and $\beta_{1}$ is the slope coefficient. $I\left(\lambda_{j}\right)$ is the periodogram at ordinate $j$. The harmonic ordinate $\lambda_{j}$ can be expressed as $\lambda_{j}=2 \pi j / T$ and $T$ is the size of the sample, $\eta_{j}$ is the error term. The OLS estimate of the slope coefficient, $\beta_{1}$ provides a consistent and asymptotically normal estimate of $d$ (Geweke, Porter-Hudak 1983). 
The findings obtained from the fractional integration method supported the results of the ADF test. The estimated fractional differencing parameter for Estonia was 1.922; the parameters for Latvia and Lithuania were 1.597 and 2.465, respectively (see Table A1). The results of the fractional integration method indicated the absence of mean reversion in the unemployment rates. As Granger and Joyeux (1980) suggested, the unemployment rate series with fractional $d$ can be closely approximated by a linear unit root model with integer number.

Table A1. Fractional differencing parameter

\begin{tabular}{ll}
\hline Country & Fractional parameter \\
\hline Estonia & $1.922[1.589,2.255]$ \\
\hline Latvia & $1.597[1.269,1.931]$ \\
\hline Lithuania & $2.465[1.724,2.291]$ \\
\hline
\end{tabular}

Note: Figures in square brackets indicate the 95 percent confidence intervals. The estimation is based on the fractional differencing model with an intercept.

An additional econometric analysis examined the persistence of the fluctuations in the Baltic countries' unemployment paths using the variance ratio persistence analysis suggested by Cochrane (1988). In this non-parametric estimation analysis the estimate is stable even when the size of the sample is relatively small (Wang 2009). The procedure was based on the polynomial of the moving average (MA) model. The MA $(q)$ model is expressed as:

$$
\Delta y_{t}=\Theta(L) \varepsilon_{t},
$$

where $\Delta$ is the difference operation and $\varepsilon_{t}$ is the error term. The moving average polynomial $\Theta(L)$ of the degree $k$ can be expressed as $\Theta(L)=1+\theta_{1} L+\ldots . .+\theta_{k} L^{k}$. In this analysis, the variance ratio statistic $\left(V R_{k}\right)$ for the persistence analysis can be expressed as:

$$
V R_{k}=\frac{1}{k} \frac{V_{k}}{V_{1}}=1+\sum_{j}^{j=k}\left(1-\frac{j}{k+1}\right) \times r_{j},
$$

where $k$ is the number of difference in the MA model, $V_{k}$ is the variance of the $k$ th difference and $V_{1}$ is the variance of the first difference of the time series, $r_{j}$ is the correlation between the $k$ th difference and the first difference.

The results of the persistence analysis confirmed the finding from the ADF tests. Figure $\mathrm{A} 1$ plots the variance ratio $\left(V R_{k}\right)$ as the function of $k$. When the unemployment rate is nonstationary, the variance increases with the number of the difference $k$. This means that the variance ratio should remain constant. On the other hand, if the unemployment rate is stationary, the variance will be constant regardless of the number of the difference $k$ and the variance ratio will decline toward zero.

As Figure A1 demonstrates, there was no decline toward zero in the variance ratio. In other words, the variance increased with the number of the difference until $k$ reached the approximate value of 13 . With $k$ greater than this value, the variance decreased according to the number of the difference $k$. However, overall, the variance ratio remained considerably higher than unity when $k$ reached 24 . These results indicate that the unemployment rates in the Baltic countries were nonstationary, which agrees with the results obtained from the $\mathrm{ADF}$ tests and the fractional integration tests. 


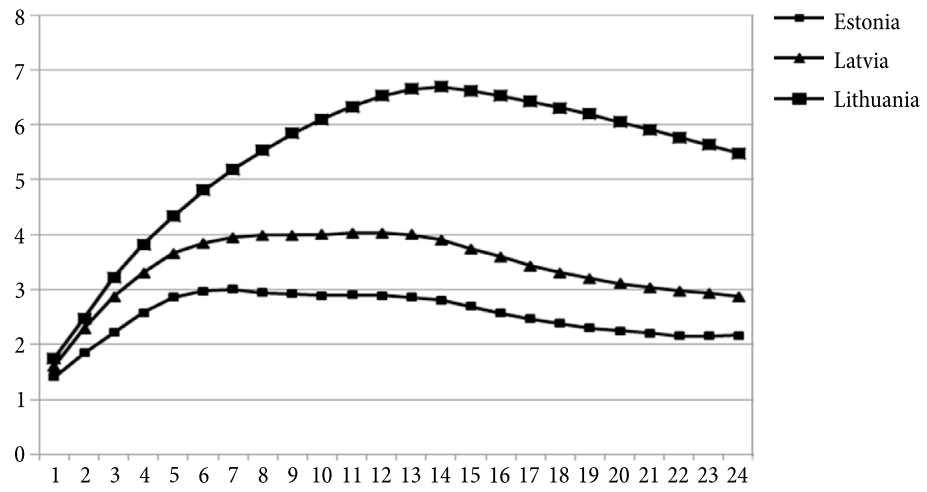

Fig. A1. Persistence analysis plot

Fumitaka FURUOKA $(\mathrm{PhD})$ is a Senior Research Fellow at Asia-Europe Institute, University of Malaya. Previous to the current position he taught economics at Universiti Malaysia Sarawak and Universiti Malaysia Sabah. He is a Life Member of the Malaysian Economic Association. Fumitaka Furuoka is the author of several books and numerous articles on economic development. 